Original Research Paper

\title{
Nuclear Energy is Renewable Energy
}

\author{
Richard Vasques \\ Universidade Federal do Rio Grande do Sul PROMEC-Escola de Engenharia \\ Av. Osvaldo Aranha, 99-4 andar 90046-900 Porto Alegre, RS, Brazil
}

The decades-long debate over whether nuclear energy can be considered clean energy does not seem to have an end in view. Naturally, no form of power generation can claim to be $100 \%$ clean-one needs only to examine the whole process involved to see that. Nevertheless, while most opponents of the nuclear-isclean-energy idea will grant that it is in fact cleaner than burning oil or coal, the generation of nuclear waste is considered to be a deal-breaker.

The issue becomes more complex due to the urgent need to reduce carbon emis-sions in a realistic (meaning economically feasible) way. OECD (2010), an analysis by the Organization for Economic Cooperation and Development and the International En-ergy Agency projected that neither wind nor solar power could outcompete gas and coal, even if a tax of 30 USD per metric ton of carbon dioxide were to be im-posed. However, the same study points out that a new generation of nuclear power is, potentially, the cheapest energy source of all.

Over the last few years, the clean-and-cheap argument over power generation has been upgraded with the idea of renewable energy. Governments use it as a political platform and the media has successfully turned it into a hot topic. To address this demand, the International Renewable Energy Agency (IRENA), an intergovernmental organization on a global scale dedicated towards the promotion of renewable energy, was founded in 2009.

But what exactly is renewable energy? In its most common de nition, renewable energy islenergy that is generated from natural processes that are continuously replenished". This usually includes sunlight, geothermal heat, wind, tides, water and various forms of biomass.

One cannot help but notice that nuclear energy is not listed above, as it is not generally considered a form of renewable energy. Amongst the arguments against including nuclear energy in the list, the most common is the fact that the deposits of uranium in the earth are nite. E ectively, it is claimed that an energy source should be sustainable for an inde nite period of time to be counted as renewable.
However, this argument misses a crucial point. Cohen (1983), in an article submitted to the American Journal of Physics, has explained how the use of breeder nuclear reactors able to generate more ssile material than they consume \{would make it possible to power the earth with nuclear energy inde nitely (Cohen explains that the word linde nitely" is intended to mean a frame of time comparable to the geological history of the earth). Moreover, since thelburning" of the nuclear fuel in a breeder reactor actually produces more fuel than it consumes, this process of generating electricity should be considered $\backslash$ renewable" \{because the fuel is continuously replenished.

Unfortunately, research in breeder reactors has been put aside for many years-mainly due to economical reasons. Since the end of the cold war, uranium has been much cheaper and more abundant than early expectations, suppressing the need for breeders. Also, the capital cost of building a breeder reactor is about $25 \%$ more than water-cooled reactors. However, interest in technology that consumes existing nuclear waste in the production of electricity is on the rise, with research related to the Generation IV reactor initiative.

Other arguments to exclude nuclear energy from the list of renewable energies are based on safety issues or the concept oflclean" energy. Helene Pelosi, the interim director General of IRENA, is quoted as saying that IRENA will not support nuclear energy because it is a long, complicated process, it produces waste and is relatively risky. These are all valid concerns; but they have nothing to do with the concept of renewable energies.

A good example of the aws in the current mindset is the fact that hydroelectric power plants, which cause huge negative impacts to the ecosystem and can produce substantial amounts of methane (WSU, 2012), are almost automatically classi ed as \renewable". One needs just to look at Brazil's hydroelectric dams (which according to the Brazilian Electricity Regulatory Agency generate nearly $67 \%$ of the country's power) to see that the concept of $\mid$ renewable" should not be so easily applied. The 
country has been battling the threat of power shortages due to lack of rains for over 12 years and has recently seen water levels dip to near critical levels (Barrucho, 2013; Blackouts, 2014).

The question that politicians and environmentalists should ask themselves is: Should nuclear energy bene $\mathrm{t}$ from some of the same subsidies and friendly policies o ered to \clean" and \renewable" energies like wind, solar and biomass? Taking into account the world's economy and the need to act now to reduce carbon emis-sions and adding to that the potential of the Generation IV reactor initiative to increase fuel e ciency while reducing nuclear waste, the answer is clearly yes. As Dr. Patrick Moore, founder of Greenpeace, once said (Moore, 2006): INuclear energy is the only non-greenhouse-gas-emitting power source that can e ectively replace fossil fu-els while satisfying the world's increasing demand for energy". To this, we add that nuclear power produced by breeder reactors is $\backslash$ renewable.

\section{References}

OECD, 2010. Projected Costs of Generating Electricity. 1st Edn., OECD Publishing, Paris, ISBN-10: 9264084304, pp: 216.

Cohen, B.L., 1983. Breeder reactors: A renewable energy source. Am. J. Phys., 51: 75-76.

WSU, 2012. New global warming culprit: Methane emissions jump dramatically during dam drawdowns, Washington State University. http://www.sciencedaily.com/releases/2012/08/1208 08081420.htm

Barrucho, L., 2013. Brazil drought stokes worries over energy shortages. BBC News Brasil. http://www.bbc.com/news/world-latin-america21055803

Blackouts, J.P., 2014. Blackouts in Brazil: Power to the people. The Economist Newspaper Limited. http://www.economist.com/node/21595872

Moore, P., 2006. Nuclear Re-Think. IAEA Bulletin 48/1. 